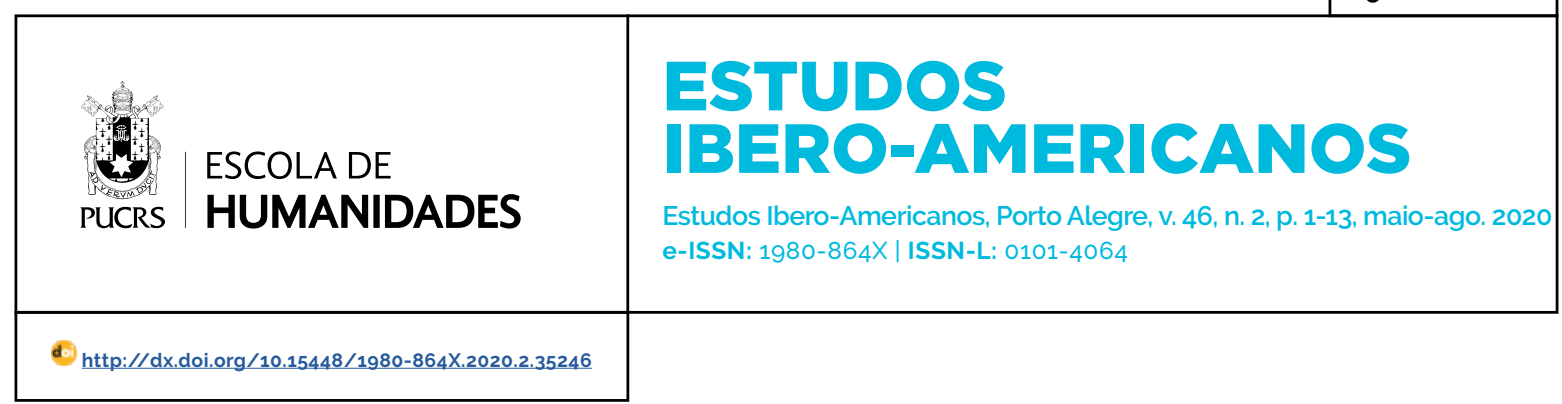

DOSSIÊ

\title{
Proyectos editoriales e iniciativas intelectuales para la circulación y legitimación del pensamiento cultural de Jorge Mañach durante la primera mitad del siglo XX cubano
}

\author{
Projetos editoriais e iniciativas intelectuais para a circulação e legitimação do \\ pensamento cultural de Jorge Mañach durante a primeira metade do século XX cubano \\ Editorial Projects and Intelectual Initiatives for the Circulation and Legimation of Jorge \\ Mañach's Cultural Thought During the First Half of the zoth Cuban Century
}

\section{Yaneidys Arencibia- \\ Coloma ${ }^{1}$}

orcid.org/0000-0003-4304-5922 yanearencibia@uo.edu.cu

Recebido em: 08 mai 2019 Aprovado em: 08 abr. 2020 Publicado em: 25 ago. 2020.
Resumen: El presente artículo revisa el panorama cultural de la primera mitad del siglo XX cubano desde una perspectiva anclada en la sociología histórica del conocimiento científico, la historia de la literatura, la ciencia y el pensamiento, la teoria del arte y la sociología de la cultura. Toma como excusa la ensayística cultural de Jorge Mañach y su vínculo con proyectos editoriales como la revista de avance e iniciativas intelectuales como la Universidad del Aire para delimitar el impacto de estos momentos en el gradual proceso de autonomia y legitimación del pensamiento cultural cubano evidente en la obra de este autor. Asimismo, contribuye a revelar las formas especificas de sociabilidad intelectual, generadas a partir de la vida y la obra de este autor.

Palabras-clave: Jorge Mañach; proyectos editoriales; Cuba; siglo XX.

Resumo: Este artigo analisa a paisagem cultural da primeira metade do século XX cubano a partir de uma perspectiva ancorada na sociologia histórica do conhecimento científico, na história da literatura, na ciência e no pensamento, na teoria da arte e na sociologia da cultura. Toma como desculpa o ensaio cultural de Jorge Mañach e sua vinculação com projetos editoriais como a revista avançada e iniciativas intelectuais como a Universidad del Aire para delimitar o impacto desses momentos no processo gradual de autonomia e legitimação do pensamento cultural cubano evidente no trabalho deste autor. Também ajuda a revelar as formas específicas de sociabilidade intelectual, geradas a partir da vida e obra deste autor.

Palavras-chave: Jorge Mañach; projetos editoriais; Cuba; século XX.

Abstract: This article reviews the cultural landscape of the first half of the Cuban twentieth century from a perspective anchored in the historical sociology of scientific knowledge, the history of literature, science and thought, art theory and the sociology of culture. It takes as an excuse the cultural essay of Jorge Mañach and his link with editorial projects such as the advance magazine and intellectual initiatives such as the Universidad del Aire to delimit the impact of these moments in the gradual process of autonomy and legitimization of the Cuban cultural thought evident in the work of this author. It also helps to reveal the specific forms of intellectual sociability, generated from the life and work of this author.

Keywords: Jorge Mañach; editorial projects; Cuba; twentieth century. 
Proyectos editoriales e iniciativas intelectuales para la legitimación del pensamiento cultural de Jorge Mañach durante la primera mitad del siglo XX cubano.

La primera mitad del siglo XX cubano es aún terreno fértil para numerosos investigadores. Para Las Ciencias del Arte, el estudio de figuras y obras constituye espacio privilegiado toda vez que permite la revisión de los contactos intelectuales y el clima de sociabilidad de la época. Así, la manera en que disciplinas como la crítica y la teoria del arte se consolidan y legitiman, al tiempo que contribuyen, desde el ejercicio de quienes las detentan, a la configuración del campo intelectual, es susceptible de nuevas miradas.

El modernismo (aún sin la necesaria modernización tecnológica) asaltó los espacios públicos y los privados, reconfiguró las distancias y las relaciones entre el campo y la ciudad, recolocó oficios, delimitó espacios (físicos y simbólicos) pero, sobre todo, movilizó las prácticas e intercambios culturales. Una buena muestra de ello es el inconmensurable número de editoriales, revistas, grupos, cenáculos y sociedades que tomaron el control de la palestra en casi todos los paises de la región.

Respaldamos la idea de que también en esta primera mitad del siglo XX una pléyade de escritores e intelectuales condujeron, desde la tradición ensayística del Nuevo Mundo, este pensamiento cultural que, sin desconocer las tendencias delas escuelas europeas al uso, gradualmente mostró sintomas de autonomía. Tal autonomía no es considerada aqui en referencia a los usos más tradicionales ya de la teoría estética, la teoria de la vanguardia, o la relativa autonomía del campo intelectual ya descrita por Bourdieu. Antes bien, se refiere a lo que probablemente sea la mayor contradicción que enfrentan históricamente los intelectuales de los paises periféricos: la aceptación acrítica de modelos explicativos nacidos en distantes horizontes semánticos (y por supuesto, culturales).

Tal autonomía cristaliza en la necesidad de explicar, describir, clasificar y, en definitiva, comprender nuestras propias prácticas artísticas. Muy a pesar de la idea de una demoradateoria latinoamericana de la cultura artística, consideramos que nombres indispensables como José Ingenieros, José Carlos Mariátegui, José Vasconcelos, Fernando Ortiz o Jorge Mañach prueban que fue posible un núcleo de pensamiento que nos ayudara a definirnos en nuestra identidad cultural.Más que suscribir entusiastamente cierto eclecticismo, en el espacio cubano al menos, se reconoce un electivismo que sirvió, desde el siglo XIX, para tomar lo mejor de cada modelo o teoría al uso, para "atacar" nuestra ya diferente realidad.

Ejemplo de este electivismo es la figura de Jorge Mañach (1898-1961), notable ensayista, periodista, firmante de la Declaración del Grupo Minorista, co-editor de la revista de avance, artifice de la Universidad del Aire, Secretario de Educación, miembro de la Academia de la Historia de Cuba y de la Academia Nacional de Artes y Letras, profesor de Historia de la Filosofia de la Universidad de La Habana, y para siempre defensor de nuestra identidad cultural. Algo que lo distinguió también en vida, fue su teoria de la circunstancialidad histórica del estilo, mediante la cual, desconociendo deliberadamente los modelos teóricos al uso en la década de 1940, demostró que los vaivenes históricos habian impactado en procesos, obras y autores para imponer lo que denominó "peculiares formas de estilización".

Su legado en la cultura cubana, ha sido reconocido a pesar de su rechazo a las ideas marxistas y su exilio hacia Puerto Rico luego de 1961. Dos de los momentos más significativos de su trayectoria, fueron su gestión editorial en la revista de avance, y la iniciativa intelectual que significó la Universidad del Aire. Con este artículo, nos proponemos tomar estos dos momentos para evaluar formas especificas de circulación de ideas y conocimientos, a través de proyectos e iniciativas que, a su vez, generaron redes de colaboración y "fermentación intelectual" (Dosse, 2007, p. 51).

En este punto resulta atractiva la idea de revelar las posiciones y tomas de posiciones al interior del campo intelectual cubano de la primera mitad del siglo XX; sin embargo, con ello se invisibilizaría la 
original contribución de Mañach a la teoría del arte. Es por ello que se privilegia un enfoque anclado en la consideración de su teoría de la circunstancialidad histórica del estilo como un conocimiento científico de segundo orden sobre la cultura artística. A partir de aqui, no se privilegiaron las polémicas o los partidismos ideo-estéticos, sino que se reconocen esta gestión editorial de la revista de avance y la iniciativa intelectual que fue la Universidad del Airecomo formas en las que también se manifiesta el pensamiento cultural de Jorge Mañach, al tiempo que se reconocen como espacios de legitimación en los que el mismo circuló.

La estrategia metodológica seguida para esta indagación, se sustenta en el paradigma hermenéutico. Al mismo tiempo, tiene una orientación necesariamente transdisciplinar, dado que se proyecta desde la sociología histórica del conocimiento científico, la historia de la literatura, la ciencia y el pensamiento y la teoría del arte ${ }^{2}$. Se privilegian la profundidad y representatividad por sobre la extensión, de ahí que solo se consideran los momentos antes referidos dentro de la prolífica vida de este intelectual.

Sobre esto mismo, se impone considerar que con relativa frecuencia se han proyectado indagaciones desde la literatura y otras disciplinas, que revisitan los proyectos editoriales. Es que estas son también espacio para el soporte material del conocimiento, al tiempo que, elementos como su presentación (visualidad, tipografia, edición, técnicas de impresión, etc.), su circulación (periodo de tiempo), así como sus integrantes (grupos, cenáculos, generaciones), nos ofrecen claves de análisis que se entrecruzan con instituciones, intelectuales e iniciativas culturales. Ello significa que constituyen espacios generadores de formas especificas de sociabilidad -no siempre en consenso- especialmente dentro del campo artístico-cultural.

Se trata de aproximaciones que se desplazan para lograr la consecución de sus objetivos, siempre desde una perspectiva fija que permite ajustar el lente de análisis. Si se trata de revistas, si se trata de instituciones, figuras relevantes, temáticas, etc., se impone el entrecruzamiento. Es virtualmente imposible estudiar la vida de las academias de la Historia de Cuba y Nacional Artes y Letras, sin analizar las publicaciones que se desplegaron como parte de su gestión. En sentido inverso, es muy difícil evaluar el lugar y la importancia de publicaciones como Verbum u Origenes, si no se toma como referencia al conjunto de intelectuales que les respaldó y a sus concepciones ideo-estéticas. Así como tampoco podría revelarse el total de la obra de un autor, sin acercarse a las instituciones y espacios en que colaboró y/o participó. Desde esta última perspectiva es que proponemos claves exegéticas para volver, no sobre los espacios de conflicto y consenso, sino sobre las instituciones, iniciativas intelectuales y proyectos de gestión editorial en los que también se configuró un pensamiento cultural.

Podemos afirmar que estamos en presencia de un entramado que editorial que "enlaza" -al mismo tiempo, es expresión de- a las instituciones, los intelectuales, las concepciones políticas, estéticas o científicas, generando espacios de sociabilidad. Esto último, a través de formas propias del campo cultural como la firma de manifiestos, la invitación a publicar, la creación de grupos, la recensión de libros, la crítica de arte, etc.

\section{La revista de avance}

Entre 1927 y 1930 transcurrió la vida de la revista de avance. De corta duración y exiguas tiradas, generada por un grupo con tradición de "minoristas", fue uno de los órganos constitutivos del vanguardismo cubano. En sus páginas se abordaron temáticas que cubrieron un espectro vasto: la cultura popular, el movimiento vanguardista, lengua nacional, negrismo, autonomía estética, nacionalismo.

A los efectos de esta indagación, se considera una forma de agrupación intelectual

\footnotetext{
2 En espacios de mayor especialización dentro de las Ciencias del Arte, se distinguen la teoría del arte de la teoría sobre el arte. La primera se refiere a las reflexiones que realizan los artistas sobre su propia praxis artística; la segunda, es construida por especialistas (no artistas) que, dentro del campo cultural, construyen teorías sobre los procesos concomitantes con la obra de arte, el artista y los públicos (Acha, 1993). Para el presente informe se emplearán indistintamente.
} 
exclusivamente dedicada a la gestión editorial ${ }^{3}$, con un alto dinamismo, debido a las posibilidades de circulación que ofrece este tipo de publicaciones. No es un elemento exclusivo de la circunstancia cubana, antes bien, es un rasgo que las redes de intelectuales compartieron a lo largo y ancho del continente. En algunos, tomaron las sólidas experiencias editoriales del Viejo Continente que traspasaron fronteras y limites editoriales, como el de la Revista de Occidente. Por otra parte, son expresión del ímpetu modernizador de la primera mitad del siglo XX y ello es evidente en las técnicas de impresión que emplearon, así como en los diseños de cubierta que presentaban.

Sale a la luz por primera vez el 15 de marzo de 1927 y se publica con periodicidad quincenal hasta noviembre del propio año. A partir de aqui aparecerá mensualmente hasta el 15 de septiembre de 1930 en que cierra su edición con el número 50. Tuvo una única interrupción en el periodo a causa del procesamiento político de José Z. Tallet y Martín Casanovas, en julio de 1927. En la declaración firmada por "Los Editores" en su última salida, se denuncia la represión contra estudiantes universitarios y la prisión de Juan Marinello. En la misma edición, también aparece:

Se rumora que, por los sucesos ocurridos, se suspenderán las garantías constitucionales instaurándose la censura previa a la prensa, en cuyo caso "1930", para no someterse a esa medida suspenderá su publicación hasta que el pensamiento pueda emitirse libremente (1930. revista de avance, 1930, p. 259).

Muy a tono con el carácter renovador, propio de publicaciones ancladas en los códigos vanguardistas, la revista incluyó el año en su denominación, al tiempo que desterró las mayúsculas de su título y el mismo cambió cada año, según fue avanzando en el tiempo. De ahí que se encuentren en bibliotecas ejemplares como 1927. revista de avance y 1929. revista de avance ${ }^{4}$. El propio Jorge Mañach, en su El estilo de la
Revolución se refería a ese espacio de consenso estético-político:

\begin{abstract}
[...] Nos emperrábamos contra las mayúsculas porque no nos era posible suprimir a los caudillos, que eran las mayúsculas de la política. Le tomábamos el pelo a Byrne, porque contribuía a la ilusión de que con la bandera bastaba para estar orgullosos. Deformábamos las imágenes en los dibujos porque lo contrario de esa deformación era el arte académico, y las academias eran baluarte de lo oficial, del favoritismo y la rutina y la mediocridad de lo oficial (Mañach, [1934] 1944, p. 97).
\end{abstract}

Desde otra perspectiva, Celina Manzoni (2001) propone que este tipo de publicaciones seriadas puede considerarse como una "obra en movimiento", y coincide con otros investigadores en que estas son un soporte indispensable en la configuración del entramado cultural de cualquier época. Carlos Altamirano sugiere que:

\begin{abstract}
Las revistas culturales han sido tradicionalmente una fuente para la historia de las ideas y la historia de la literatura. A través de ellas se pueden estudiar las direcciones y las batallas del pensamiento en las sociedades modernas y hacer el mapa de las líneas de sensibilidad de una cultura en un momento dado. Pero las revistas son también una forma de agrupamiento y organización de la intelligentsia (Altamirano, 2010, p. 19).
\end{abstract}

En este sentido, cada revista se delimita a sí misma en relación limítrofe con otras del mismo periodo. Manzoni (2001) y Terán (2010), se han referido a las relaciones que el grupo cultural que da origen a la revista, establece con sus similares y con la sociedad en general. Con ello se confirma también, el lugar privilegiado que tiene el estudio de una revista como avance, a la hora de determinar su lugar dentro del conjunto de factores externos actuantes sobre el pensamiento cultural de Jorge Mañach.

Es entonces, un factor externo que actúa directamente sobre la emergencia y la consolidación del pensamiento cultural de este intelectual. Si bien a las páginas de la revista

\footnotetext{
3 A diferencia de otras formas de iniciativas intelectuales e instituciones académicas cuyo objetivo primero no contemplaba la edición de textos, sino que esto formaba parte de estrategias de socialización y reproducción del conocimiento. Ejemplo de ello fueron los Cuadernos de la Universidad del Aire y las Actas de las academias de la Historia de Cuba y de Artes y Letras.

4 Juan Acha ha explicado que el movimiento vanguardista latinoamericano no solo negó su antecedente estético-formal academicista, sino que, en esa violencia simbólica, negaba también la historia colonial que ello significaba (Acha, 1993).
} 
de avance pertenecen textos de lo que podría denominarse primera etapa del pensamiento cultural mañachiano 5 , sin dudas la existencia de la misma sirvió de soporte a la "inquietud cubana"6. Se convirtió en un espacio de legitimación -al tiempo que, de consenso y disenso- sobre cuestiones que reflejaban el tono y las preocupaciones de la élite intelectual cubana de la época.

Si bien Manzoni se refiere a la misma como un espacio privilegiado para la proliferación del ensayismo (Manzoni, 2001), lo cierto es que este género ya se había consolidado en el continente como soporte material de las reflexiones culturalistas de imprescindibles como Sarmiento, Bello, Ingenieros, Mariátegui, Vasconcelos, entre muchos. Es así que, más que referirnos a la misma como plataforma para un género o tribuna para la avanzada vanguardista cubana, nos proponemos revisitarla como un especio que contribuyó a la emergencia de un pensamiento cultural, modelándolo desde su función y estructura.

La revista de avancetuvo, lo que se conoce en el circuito editorial como una "vida breve" que, a su vez, se ha atribuido a factores externos de diversa indole, especialmente los financieros y los relacionados con la represión durante el machadato. Acaso esta circunstancia histórica, incidió negativamente en la consolidación de un espacio de convergencia reflexiva en torno a la cultura artística cubana y latinoamericana.

Es que las revistas, se confirman mediante la configuración de espacios de creación colectiva en los que convergen competencias disimiles. En el vórtice de los inicios del movimiento vanguardista cubano, in extenso, la revista de avance contribuyó a la consolidación de tal espacio, no solo desde la declaratoria en letra impresa, sino también desde las redes de relaciones que se establecieron sincrónica y diacrónicamente, con respecto a su ciclo vital.

Su espacio de circulación efectiva no fue muy amplio -cuestión que puede deducirse del número de tiradas por cada númeroestaba dirigida, fundamentalmente a un público ya entronizado en las cuestiones relativas al vanguardismo y la militancia politica intelectual. Contó con mecanismos de distribución que Martín Bergel y Ricardo Martínez (2010), han identificado como formas prototipicas de sociabilidad intelectual en Latinoamérica a partir de la gestión editorial de las revistas. Es así que, "contaban con mecanismos de distribución más o menos informales que, eran de crucial importancia en la factura de un extendido mapa de lectores en todo el continente" (Bergel y Martínez, 2010, p. 134).Esto mismo no sucedía entonces cuando los intelectuales reproducian sus reflexiones desde otros espacios de circulación más o menos relacionados con los ideales estéticos más avanzados de la época.

Un atisbo de ello es que el propio Jorge Mañach, comparte espacio - de consenso, legitimación y partidismo estético- con la pluma de Juan Marinello que, incluso dentro de la historia de la literatura cubana, se escinde para su estudio en autores marxistas y no marxistas. En tal sentido, también es justo atender que, el primero, vuelve sobre estas temáticas de carácter estético, desde el horizonte teórico, casi diez años después con "El estilo de la Revolución", publicado en 1934, precisamente, en las páginas del Diario de la Marina. Las distancias entre los objetivos, alcance, funciones y partidismos entre el Diario de la Marina y revista de avance son más que evidentes. Sin embargo, Mañach no se permite desaprovechar espacios editoriales para la socialización de sus reflexiones sobre la cultura artística cubana.

Uno de los momentos más significativos que se convierte, al mismo tiempo, en espacio de confrontación acerca de temáticas relacionadas con la autonomía estética y expresión del alcance (intelectual y editorial) de la revista de avance se da entre 1927 y 1928, alrededor del debate en torno al meridiano intelectual de América Latina. Guillermo

\footnotetext{
5 No ha sido objetivo de la presente investigación establecer una periodización del pensamiento cultural mañachiano atendiendo a las temáticas abordadas o a la trayectoria del mismo. Sin embargo, la propia "vida" de la revista de avance (1927-1930) coincide con la etapa de juventud de Jorge Mañach.

6 Con esta denominación Juan Marinello identificaba al conjunto de preocupaciones de los jóvenes intelectuales, escritores y artistas cubanos de la época.
} 
de la Torre propone al director de Repertorio Americano. Semanario de Cultura Hispánica que reproduzca un editorial de La Gaceta Literaria de Madrid titulado "Madrid, meridiano intelectual de Hispanoamérica". Ello despierta reacciones encontradas, cuyas pistas pueden seguirse desde publicaciones como Martín Fierro de Buenos Aires, La Pluma de Montevideo o Excelsior de México (Manzoni, 2001, p. 296-301).

La revista de avance entra en al debate en septiembre de 1927 y lo continua en noviembre del propio año (1927 revista de avance, 1927: 273274 y 1927 revista de avance, 1927: 112). Pero lo más significativo es que las palabras aparecen en la sección DIRECTRICES, dedicada a exponer los criterios de los editores. Tómese en cuenta que, en este grupo gestor, están los nombres de Juan Marinello y Jorge Mañach. Si bien ambos recorrieron trayectorias ideológicas cada vez más distantes, entre ellos mismos y con respecto a Ichaso y Carpentier -durante y después de la edición de avance- los cierto es que la preocupación y ocupación por la independencia estética latinoamericana y cubana, fue una constante en la obra de todos y cada uno de ellos.

Esto último, puede confirmarse a través de las páginas del proyecto editorial que acompañó a este rotativo: los Cuadernos Mensuales de Trentidós Páginas [sic]. Estos fueron pequeños folletos -de muy dificilacceso en la actualidad- publicados bajo autoria individual, y dedicados a temas especificos o que habian sido tocados en la revista. En 1928, como parte de este espacio, Jorge Mañach publica Goya, en el que hace un recorrido histórico-crítico por la obra del pintor español?. Entre los diversos temas, está también Sobre la inquietud cubana, de Juan Marinello, en donde su autor recorre las preocupaciones que considera puntuales con respecto al arte de las vanguardias, desde la perspectiva cubana y hace una discreta alusión al tema del meridiano intelectual de América.

En buena medida, puede representarse a la revista de avance no solo como un proyecto editorial de iniciativa grupal (Fornet, 2016), sino como una plataforma para la socialización y legitimación de paradigmas estéticos. Igualmente, fueron legitimados cada uno de los editores de la revista, como personalidades que años después, sentaron pauta en animados debates -como es el caso de la polémica entre Mañach y el grupo Orígeneso en la "beatificación" de obras y/o autores. De esto último, es representativa la inclusión, por Juan Marinello, de Don Segundo Sombra, como modelo de a novela latinoamericana en su artículo "Tres novelas ejemplares", publicado en otra revista cultural de importancia continental: Sur, en 1936 (Manzoni, 2001).

Estos elementos, sirven para confirmar la idea de que determinados elementos del panorama editorial cubano de la República, reprodujo un sistema de relaciones con intrincados espacios de sociabilidad, alrededor de los proyectos editoriales como la revista de avance. Ello sirvió para legitimar discursos y jerarquizar autores. Al mismo tiempo, sirvió de plataforma a la emergencia del pensamiento cultural de Jorge Mañach, en buena medida, debido a la necesidad de exponerse ante un público también de élite y también más masivo.

Del análisis de este espacio -devenido institución de la cultura cubana de la épocase deduce su impacto en la emergencia del pensamiento cultural mañachiano pues reconoce a este intelectual como un actor social, gestor de un espacio editorial de envergadura e impacto. La importancia de esta publicación seriada para el vanguardismo cubano fue notable (ILL, 2003: Manzoni, 2001) pues constituyó espacio de legitimación de posturas ideo-estéticas transgresoras para la época.

En términos formales, impactó en la estructura de los textos debido a que los autores (Mañach, por ejemplo) contaban con un espacio especifico que debía contener con precisión la idea que quería transmitirse. Lo anterior, por supuesto, impacta en la propia concepción del texto como una unidad monolítica ${ }^{8}$. Ello también implica

\footnotetext{
Si bien este título podria inscribirse dentro de las coordenadas del pensamiento cultural de Jorge Mañach, a los efectos de esta indagación, solo se toman en cuenta los textos referidos especificamente al arte y la cultura cubanas.

8 Tómese como referencia los tres primeros números de la revista de avance donde, aparece un ensayo de Jorge Mañach dedicado a vanguardismo y al compromiso del artista y el intelectual con su época.
} 
alteraciones en la difusión y recepción por parte del público. Existen obvias diferencias entre Goya y otros textos publicados dentro de la gestión editorial de la revista como parte de los Cuadernos de trentidós[sic] páginas, a diferencia de sus números ordinarios entre 1927 y 1930.

Esto es muestra de que, la gestión editorial de tipo privado, resultó de vital importancia para la socialización y legitimación de códigos estéticos, respaldados por un espacio de intercambio y reproducción de los mismos. Si bien, dentro de la curva evolutiva del pensamiento cultural mañachiano, esto pertenecería a la primera etapa, su impronta en la emergencia y consolidación del mismo resulta innegable.

\section{La Universidad el Aire}

Al ser la radio un medio de amplio alcance, desde su fundación, artistas e intelectuales la emplearon como medio o herramienta para llegar a un público vasto. La Universidad del Aire se destacó en dicho empeño. Inició sus transmisiones el 13 de diciembre de 1932, bajo la dirección y organización de Jorge Mañach, en un entorno donde la gestión cultural oficial era muy limitada.

Se conceptúa como una iniciativa intelectual de carácter privado, pues, tanto el propio medio radial como la organización y gestión de esta, excedian los limites y gestión estatales. No puede afirmarse que fuera la primera experiencia de este tipo en Cuba, debido a que, con anterioridad, se transmitió la Universidad Popular (1923-1927), idea original de Emilio Roig.

Estas agrupaciones espontáneas de intelectuales, organizados en torno a una idea como es el caso de la Sociedad de Conferencias, la revista de avance o la Sociedad Pro Arte Musicalpor lo general, mantenian objetivos orientados al desarrollo de proyectos culturales de largo alcance. Esto, por supuesto, estaba mediado por, al menos, dos aspectos fundamentales: el libre asociacionismo (declarado desde la Constitución de 1901) y los críticos indicadores de cultura hacia la primera mitad del siglo XX cubano.

Esta iniciativa intelectual consistía en una serie de conferencias articuladas en cursos, impartidas por profesores universitarios, miembros de las academias de la Historia de Cuba y Nacional de Artes y Letras, asi como otros prestigiosos intelectuales cubanos y extranjeros. Desde sus inicios, se planteó como objetivo principal, despertar en los oyentes un interés en los temas de la cultura. Sin la intención manifiesta de impartir conocimientos profundos y detallados, sino más bien, nociones introductorias y generales que abriesen una vía inicial a la curiosidad.

Esto obedecía a dos razones fundamentales: la necesidad de llegar de manera sencilla y amena a la mayoria de la población, y el tiempo del que se disponía. De esta manera, se daba respuesta a las necesidades culturales y educativas del pais, a través de un medio que permitía el acceso a la amplia masa iletrada de cubanos, y que brindaba amplias posibilidades socializadoras e influenciadoras.

En este sentido, al mismo tiempo, da cuenta de la coherencia entre pensamiento y acción en el joven Jorge Mañach. Uno de los fundamentos de su conferencia La crisis de la alta cultura en Cuba (1925), habia sido precisamente, la necesidad de elevar el nivel cultural de la mayoria de la población cubana. Esta idea -heredera del ideal de cultura de la llustración y del apostolado martiano- fue recurrente entre intelectuales de la época y, animó otras iniciativas intelectuales durante todo el periodo republicano.

El programa constó de dos etapas; la primera de diciembre de 1932 a octubre de 1933, con transmisión los martes y viernes de 9:00 a 10:00 p.m., por la emisora CMBZ9. La segunda inició el 9 de enero de 1949, esta vez, por la emisora CMQ - la de mayor audición en Cuba en la época (López, 1998) -, los domingos de 3:00 a 4:00 p.m., hasta 1960, fecha en que cesó el programa.

Cada emisión radiada disponía de dos conferencias, con una duración de 20 minutos, separadas por un intermedio musical. Díaz Acostaha hecho notar que, se procuraba una ambientación musical en correspondencia con cierta afinidad histórica o estética a los temas

9 Casa El Mundo-Salas, propiedad de Manuel y Guillermo Salas. 
desarrollados (Díaz, 2001). Dichas conferencias, eran grabadas a medida que salian al aire, dando lugar a los Cuadernos de la Universidad del Aire. De esta manera, ponian al alcance de los oyentes, y a un precio módico -20 centavos - los textos impresos de los programas (Díaz, 2001). En la mayoría de los casos, se acompañaba de una pequeña lista de obras de consulta,sobre el tema en cuestión, preparada por cada conferencista.

Revisar dicha bibliografía y los títulos de las disertaciones, permite apreciar el espectro temático recorrido. Temas históricos, filosóficos, sociológicos, artísticos, literarios, científicos y de otras disciplinas, encontraron en esta iniciativa intelectual, un espacio primario. El complemento de estos dos medios - radial y escrito- permitió el acceso a amplios sectores del país. El primero de estos, resultó especialmente eficaz, si se tiene en cuenta el alto índice de analfabetismo en Cuba. A cargo de Mañach, estaban también los Cuadernos..., quien se auxiliaba en Francisco Ichaso y Luis A. Baralt. También los interesados, podian comunicarse vía correspondencia, con los conferencistas (Díaz, 2001).

En la conferencia inaugural, pronunciada su organizador en diciembre de 1932, se precisaron los propósitos y métodos. Según sus palabras, dicho empeño académico aspiraba "a sacar la enseñanza del coto privilegiado de las aulas y ponerla, siquiera sea en forma elemental, donde todos puedan alcanzarla" (Díaz, 2001). Según Mañach, Cuba poseía una gran necesidad educacional, y esta era, generalizar los conocimientos para que llegasen a todos, ampliando de esta forma el repertorio de ellos para fecundar la curiosidad con múltiples semillas. A esta imperiosa tarea, aspiraba a contribuir la Universidad del Aire.

Los cuadernos correspondientes a cada curso de esta la época, fueron numerados consecutivamente, y a partir del número 11, aparecieron con el subtítulo Publicación Semanal. El programa se vio obligado a interrumpir sus tareas debido a la inestabilidad política por la que atravesaba el país, tras la no consolidación del gobierno revolucionario que había dado al traste con la dictadura de Gerardo Machado el 12 de agosto de 1933.

En los años intermedios entre el '33 y el '49, la radio creció y se desarrolló. Como resultado de la abolición de la Enmienda Platt en 1934, y la firma de un nuevo Tratado de Reciprocidad Comercial que posibilitaba el incremento de la presencia de productos norteamericanos en el mercado cubano, se produce un aumento en las importaciones, y esos productos, que entran al mercado en libre competencia, comienzan a precisar publicidad comercial, y encuentran en la radio su instrumento más eficaz ${ }^{10}$.

Durante la segunda etapa, aunque el programa mantenía un formato similar al de la anterior — con la excepción de que en esta ocasión el público acudía al estudio de grabación y podía realizar preguntas generando un oportuno debate-. no se mencionó el esfuerzo inicial de los años 1932 y 1933. A lo largo y ancho de la Isla, el programa fue adquiriendo gran popularidad, llegándose a fundar grupos de Amigos de la Universidad del Aire en distintas poblaciones del país (Díaz, 2001). Conquistó cobertura nacional e internacional, sentando importantes primacias en la radiodifusión, pues sus emisiones se transmitian por la NBC norteamericana (Díaz, 2001).

Los cuadernos se imprimieron bajo el nombre de Cuadernos de la Universidad del Aire del Circuito $C M Q$, adquiriendo un formato menor, pero manteniendo la misma composición tipográfica y reproduciendo en el reverso de la portada el mismo fragmento del Reglamento de la Universidad del Aire que durante la primera temporada, y a partir de 1951 aparecieron con el subtítulo Mensuario de divulgación cultural. En 1952 dejaron de publicarse, aludiendo razones económicas, y el tiempo de duración del programa fue reducido ${ }^{11}$.

Gran parte del desarrollo de la Universidad del Aire, en su segunda etapa, transitó de forma

\footnotetext{
10 Se inicia con ello el periodo comercial del medio, que aniquila la etapa romántica. No obstante, entre las prácticas mediáticas que caracterizaron a la Universidad del Aire, está el hecho de que en su hora de emisión no se difundían mensajes comerciales (López, 1993). ${ }_{11}$ Por temor a que la popularidad del espacio descendiera hasta desaparecer, Mañach escribió una carta al doctor GoarMestre, director de $C M Q$, en la que le proponía un proyecto de programa cultural de televisión, asistido por la Universidad del Aire, bajo el título de Invitación a la Lectura, con transmisión radial simultánea por CMQ. Dicho proyecto tuvo que ser abandonado por no recibir apoyo ni atención.
} 
paralela a la dictadura de Fulgencio Batista, y no son pocos los hechos que tuvieron como escenario al teatro-estudio de $\mathrm{CMQ}$, hechos que estaban estrechamente vinculados con la política represiva de la dictadura batistiana o con el sentimiento nacional de oposición a la misma, ya que como resultado del golpe de Estado, muchos jóvenes acudian al programa con el objetivo de utilizarlo para denunciar el régimen de facto. A pesar de la férrea censura desatada que amordazaba la prensa, la Universidad del Aire, continuó siendo rectora de temas vinculados a la cultura y la educación, además de abordar otros de interés universal y problemas de carácter nacional.

Oscar Luis López, quien fuera productor del programa, en su libro La radio en Cuba, recuerda que en una ocasión el cristal que los separaba del estudio les impidió ser blanco de una lluvia de huevos lanzados contra Raúl Cremata Valdés, quien habia tratado de justificar el cuartelazo del 10 de marzo. "Ese día las puertas del estudio dos se abrieron para dar salida no sólo al público que se atemorizó, temiendo la llegada de las perseguidoras, sino a los autores del hecho, que no eran otros que un grupo de estudiantes que estaban cazando al paniaguado que hacía su comparecencia" (López, 1998, p. 37).

El 4 de mayo de 1952, como parte del curso No. VI, titulado Curso del cincuentenario, Elias Entralgo presentó "Saldo del Cincuentenario", donde examinaba todo el proceso histórico vivido en la primera mitad de siglo. Durante la misma, Raúl Tamayo Rodriguez ${ }^{12}$, lo interrumpió y subió al escenario junto a un grupo de batistianos amparados por la policia. Fueron agredidos Mañach y Gerardo Canet, profesor de Segunda Enseñanza, el propio Entralgo, asi como los entonces líderes estudiantiles Faustino Pérez Hernández y Armando Hart Dávalos. Este suceso constituyó una de las primeras acciones brutales de la tirania después del golpe de Estado, y tuvo una enorme repercusión social, que se expresó en ola de protesta popular.

Lo anterior, sin dudas, también es muestra del alcance que tuvo el programa. Sirve para confirmar la trascendencia que pudieron tener los programas radiales de la Universidad del Aire. Se trataba de un espacio de difusión de conocimientos y, también, de reproducción de ideologías que participaban de la construcción histórica de la nacionalidad cubana. Ello puede confirmarse también en los nombres de varios de los conferencistas, miembros de las academias.

Mañach no solo fue director de la Universidad del Aire, sino además, conferencista, conductor, moderadory seleccionador de temas e invitados, constituyendo así, el alma de la institución. No obstante, según consta en su expediente laboral, desde 1952 hasta 1959, permaneció largas temporadas en el extranjero - con licencias por motivos de salud o personales-; en su ausencia lo sustituyó el doctor Francisco Ichaso, y tras el triunfo revolucionario, Luis Aguilar León, hasta 1960, fecha en que cesó el programa.

En buena medida, esto puede reconocerse como un intento de dar solución a algunos de los problemas más acuciantes que habia identificado Jorge Mañach en su conferencia La crisis de la alta cultura en Cuba de 1925. El medio radial, ofrecía un espacio de largo alcance, sin necesidad de que la población estuviera alfabetizada. Por otra parte, el carácter de los cursos, da cuenta de que estos estaban pensados para diferentes niveles de conocimiento; asimismo, algunos de los más prominentes intelectuales de la época se vincularon a este empeño compartiendo, obviamente, los objetivos.

Aqui se impone apuntar que esta forma específica de sociabilidad intelectual, nucleada en torno a una iniciativa intelectual de gestión privada, resulta un excelente ejemplo de las amplias posibilidades que ofrece la libre asociación y la posibilidad de hacer funcionar el empeño a través de una intrincada red de relaciones entre intelectuales. Cuando se revisan los nombres de los conferencistas, puede apreciarse que se repiten en algunas de las instituciones de cultura -con respaldo gubernamental o no- lo que coloca a la Universidad del Aire como canal

${ }_{12}$ Presidente de la sección juvenil del partido del Gobierno en la provincia de Oriente y cabecilla de varios actos vandálicos en Santiago de Cuba 
de socialización y difusión de las ideas de sus cursistas. Algunos de estos pertenecian a las academias de la Historia de Cuba, de la Lengua y Nacional de Artes y Letras, además de alternar sus labores como abogados, periodistas o docentes.

Nombres como Fernando Ortiz, Juan Marinello, Raúl Roa, Rosario Novoa, entre otros, impartieron cursos radiados sobre temáticas que abarcaron la historia de Cuba, el arte griego, la historia de la filosofía o la filosofía contemporánea, hasta temas de literatura y folclor. Este sistema de trabajo y presentación de cursos, agrupados por temáticas, da cuenta de una red sostenida por formas de sociabilidad en las que podian concurrir estos intelectuales con independencia de su proyección ideológica o política.

Esta forma especifica de iniciativa intelectual, impactó en el proceso de consolidación del pensamiento cultural mañachiano, toda vez que consolidó su lugar en el entramado de la intelectualidad cubana de la época. Es un buen ejemplo de especificas formas de sociabilidad académica y reproducción del conocimiento a través de un medio accesible a amplias zonas de la sociedad cubana. Por otra parte, al igual que las publicaciones seriadas, impuso una lógica estructuradora a los textos $-y$, consiguientemente, a los contenidos- puesto que contaban con un especifico tiempo de duración al aire y se pensaban para cualquier tipo de público.

Es, en la trayectoria mañachiana, la gestión cultural más extensa en el tiempo y de mayor alcance, dadas las posibilidades comunicativas de un medio como la radio. Tuvo una función esencialmente educativa y comunicativa; y reprodujo otras variantes de circulación del conocimiento, gracias a la gestión editorial de los Cuadernos de la Universidad del Aire.

\section{Otros espacios para la legitimación del pensamiento cultural}

En suma, puede argüirse el impacto de estos dos espacios de la primera mitad del siglo XX cubano en la consolidación y legitimación del pensamiento cultural de Jorge Mañach. La revista de avance y la Universidad del Aire actúan como instituciones a las que se vinculó este autor, y pueden visualizarse también como formas especificas de sociabilidad, deducibles, a partir del entramado editorial. Así como los Cuadernos de la Universidad del Aire, como soporte material de esta iniciativa intelectual, contribuyeron a la institucionalización de la Filosofía en Cuba; del mismo modo, la revista de avance, respaldó la plataforma de los códigos vanguardistas a fines de la década del veinte.

También son expresión de vínculos asociacionistas como los cenáculos (característicos de agrupaciones literarias), las sociedades culturales, los grupos, etc. Estos también, ensanchan la trama de la intelectualidad y sus espacios de legitimación a través de publicaciones (seriadas o no), invitaciones a cenas y almuerzos, la lectura de discursos, entre otras estrategias de sociabilidad que, a la postre, sirven para cohesionar el espacio constitutivo que, al mismo tiempo, confirmala relativa autonomía epistémica del pensamiento cultural mañachiano ${ }^{13}$.

Un ejemplo notable de la complejidad de las relaciones dentro de este entramado, lo aporta Celina Manzoni en Un dilema cubano. Nacionalismo y vanguardia (2001) cuando refiere que, desde Social se llegaron a publicar páginas que incluyeron tanto la Declaración del Grupo Minorista como "Fantoches 1926. Folletín moderno por doce escritores cubanos". Otras revistas que dieron cabida a las inquietudes de los jóvenes intelectuales fueron Revista Bimestre Cubana, dirigida por Fernando Ortiz y Cuba Contemporánea fundada por Carlos Velasco y Mario Guiral Moreno (Manzoni, 2001).

De la lectura atenta de las noticias publicadas en las páginas de estos y otros ejemplos notables -como es el caso de Orto publicación manzanillera de alcance nacional en el periodose deducen relaciones y espacios más o menos fijos de sociabilidad, generados por estos grupos: colaboraciones, almuerzos, cenas,

13 Esta idea de un vínculo entre las instituciones, las formas en que se organizan los intelectuales y las estrategias que ello genera, puede seguirse también a partir del análisis de Antonio Gramsci en Los intelectuales y la organización de la cultura (1972). Es aqui donde el autor presenta la idea del agrupamiento intelectual como un "edificio cultural completo y autárquico" (Gramsci, 1972, p. 98) 
conferencias, invitaciones o noticias culturales. También resulta interesante el modo en que se repiten con insistencia ciertos nombres en estos mismos espacios: Emilio Roig, Fernando Ortiz, Jorge Mañach, Juan Marinello, entre tantos otros. Estrategias de sociabilidad que, si bien presentan un reverdecer en los inicios de la década del veinte, se mantendrán en la práctica de estos mismos intelectuales durante su participación en la gestión de la revista de avance y con posterioridad al fin de su edición en 1930.

No solo desde el proyecto editorial gestado como iniciativa intelectual en 1927 pueden deducirse espacios de sociabilidad. Carlos Altamirano da cuenta de lo que denomina red intelectual que "indica una forma de sociabilidad y una cadena de contactos e interacción entre artistas, gente de letras, editores y otros tipos de agentes culturales, ligados por convicciones ideológicas o estéticas compartidas" (Altamirano, 2010, p. 19). La propia noción de red nos coloca ante la posibilidad de visualizar formas de comunicación y trayectorias de ideas que conectan a individuos y grupos en localizaciones geográficas diferentes y hasta multitemporales.

Tómese en cuenta que no se pretende de una cronología -exhaustiva o intensa- de las actividades y la labor desplegada por Jorge Mañach o sus contemporáneos. Todo esto ha sido descrito por historiadores, literatos, bibliógrafos, etc. En cualquier caso, se trata de, mediante las claves de análisis que ofrece la sociología del conocimiento cientíico, determinar cuálesy de qué manera pueden haber influido en la emergencia y posterior consolidación del pensamiento cultural mañachiano.

Se impone volver la mirada sobre el panorama editorial del periodo y evaluar las formas de la sociabilidad que se generaron. Estas pueden seguirse desde el rastreo bibliográfico de los textos publicados en la época y los posteriores. Se debe tener en cuenta que, en ciertos espacios se trató de respaldar un ideal común -casi siempre estético- a pesar de las abiertas distancias ideológicas o el partidismo en corrientes que, aunque no antagónicas, tampoco entrecruzables.

El proyecto editorial que fue la revista de avance, se proyectó como un espacio de consenso ideoestético en torno a cuestiones relacionadas con el vanguardismo y la cultura artística (cubana, latinoamericana y universal), muy a pesar de las distancias ideo-políticas de integrantes como Juan Marinello, Jorge Mañach, Martín Casanovas, José Z. Tallet, Francisco Ichaso, Félix Lizaso, e incluso, en un periodo de tiempo, Alejo Carpentier $^{14}$. La posterior trayectoria intelectual de cada uno de ellos, así como los antagonismos abiertos -que dentro del campo intelectual se denominan "polémicas"- demuestra que, en el seno de cada una de estas estructuras (proyectos editoriales, academias, iniciativas intelectuales) se reproducian complejos sistemas de relaciones para legitimar una específica zona de consenso al mismo tiempo, en otras coordenadas (temporales o espaciales) afloraban los disensos.

A modo de ejemplo, Alberto Lamar Schweyer, uno de los fundadores del Grupo Minorista, se alejó de la actividad pública del mismo por su filiación con Gerardo Machado. Por otra parte, Alejo Carpentier colaboraba con el reaccionario Diario de la Marina (bibliografía de Alejo Carpentier), aunque sufrió prisión durante el machadato debido a su actividad política.

No solo se confirma la idea aqui trazada de un denso entramado de relaciones de conflicto y consenso militante en lo estético y lo político cuando se toman como referencia las relaciones entre los miembros de una iniciativa intelectual, un grupo de gestión editorial o de una academia. En 1927. Regino Boti critica duramente al minorismo y considera su falta de propuestas estéticas concretas y su ausencia de origenes. Sin embargo, Jorge Mañach se refiere, a raíz del encuentro con un "Grupo Minorista" en Matanzas -al que se afilió Medardo Vitier (Manzoni, 2001)- que la organización proponía colaboraciones individuales en otros rotativos (como Social) y la recepción de visitantes ilustres (Cairo, 1989; Manzoni, 2001).

14 Para una cronología de la evolución del equipo editorial de la revista de avance, se sugiere la lectura de Un dilema cubano. Nacionalismo y vanguardia, de Celina Manzoni (2001). 
Las redes de relaciones y los espacios de conflicto y consenso pueden seguirse en los años posteriores a 1923 y a 1927. Emilio Roig publica en Social un conjunto de textos que durante el año 1929 refirió el itinerario y la disolución del Grupo Minorista. En los números 6, 9 y 10 (junio, septiembre y octubre, respectivamente) el notable intelectual da cuenta de su trayectoria política e ideo-estética, al tiempo que legitima su paso efimero por la historia de Cuba al inmortalizarlo desde las páginas de este rotativo. No resulta sorprendente entonces, descubrir que todos los miembros permanentes del equipo editorial de la revista de avance habian firmado en 1923 la Declaración del Grupo Minorista (Cairo, 1978; Manzoni, 2001; ILL, 2003).

Sobre el propio vanguardismo, del cual Avance seria una suerte de órgano programático, también Mario Guiral Moreno reflexionó años después en su discurso de asunción como presidente de la Academia Nacional de Artes y Letras, en donde agravió largamente el alcance del movimiento. Es que, si se encuadra la mirada desde la actividad de las academias, también se divisa un apretado entramado de relaciones, generadoras de espacios concretos de sociabilidad, a partir de los proyectos editoriales. No solo la publicación de los respectivos Anales de cada una, sino por el despliegue editorial que también ofrecieron. Publicaron en separatas o folletos, los discursos de ingreso y de respuesta, leidos en recepciones públicas. Cada uno, como pequeño libro operó como "uno de los soportes de inscripción y de circulación del discurso intelectual" (Altamirano, 2010, p. 23).

También las academias - dentro del rango de acción normativa- funcionaron como espacios generadores de formas especificas de sociabilidad y legitimación del discurso. Se impone destacar las conferencias de divulgación literaria y los certámenes públicos a que convocaba la Academia Nacional de Artes y Letras para premiar a escritores, poetas, historiadores, críticos, músicos, pintores, escultores y arquitectos. Además, estuvo presente en significativos actos de trascendencia cultural, como la inauguración, en México, de la Ciudad Universitaria, en 1952.
Dentro delanterior aspecto (el panorama editorial) los Anales de la Academia Nacional de Artes y Letras, fue una publicación trimestral que surgió como órgano oficial de la institución que la patrocinaba, con la finalidad de insertar en sus páginas sólo los trabajos leidos en sesiones de la corporación, públicas o privadas; los presentados por sus miembros, aprobados previamente por la Academia o por la sección respectiva; y los documentos relacionados con la vida de la corporación o el desenvolvimiento de sus actividades.

Desde otra perspectiva, en el circuito editorial, también se generan formas de sociabilidad más institucionales (menos informales) que relacionan a las revistas con otras de su clase y género. De las referencias, el estudio atento de los equipos editoriales, de la lectura de los anuncios y noticias de la época, pueden deducirse puentes que relacionan a más de un intelectual, mercados para la publicidad académica o gestión colaborativa. Juan Marinello y Jorge Mañach promocionan desde los primeros números de la revista sus propios libros (Liberación y Estampas de San Cristóbal respectivamente). El equipo editorial invita a viñetistas y diseñadores como Mariano y Abela, comprometidos con la nueva visualidad modernista. Convocan a importantes intelectuales de la época, pues:

\begin{abstract}
Es improbable que una revista sea sólo el reflejo de un emprendimiento individual. Por lo general, sus páginas incorporan la actividad cooperativa de una serie de personas (la de un círculo ideológico, la de un grupo literario, o un conjunto más laxo), aunque algunas de esas personas tengan mayor ascendiente o ejerzan el liderazgo intelectual sobre el resto, al punto que la revisa sea indisociable de su nombre, como Amauta lo es de José Carlos Mariátegui (Altamirano, 2010, p. 20).
\end{abstract}

En tal sentido, se trata de instituciones generadoras de un entramado que soporta especificas formas de sociabilidad, distintivas de los actores que de ellas participan. Tales formas, su impacto y alcance en la primera mitad del siglo XX cubano, confirman su importancia para la circulación y legitimación del pensamiento cultural de Jorge Mañach.

Al mismo tiempo, resulta razonable visualizarles como manifestaciones del pensamiento cultural 
mañachiano, no solo rastreable desde los ensayos y discursos, sino visible también desde estas iniciativas intelectuales y gestiones editoriales. La "maleabilidad" de los textos (que no de los temas) nos habla de soportes que reconfiguraron, desde lo formal, la altura argumentativa de Jorge Mañach. Esto es visible en las obvias distancias entre "Vanguardismo" (1927) y "El estilo de la Revolución".

\section{Referencias}

ACHA, J. Las culturas estéticas en América Latina. México D. F.: UNAM, 1993.

ALTAMIRANO, C. Élites culturales en el siglo XX latinoamericano Historia de los intelectuales en América Latina Argentina: Katz Editores. v. II, p. 9-28, 2010.

BERGEL, M.:. MAZZOLA, R. M. América Latina como práctica. Modos de sociabilidad intelectual de los reformistas universitarios (1918-1930). Historia de los intelectuales en América Argentina: Katz Editores, 2010. v. 2.

CAIRO BALLESTER, A. El Grupo Minorista y su tiempo. La Habana: Ciencias Sociales, 1979.

DÍAZ ACOSTA, N. Universidad del Aire (conferencias y cursos). La Habana: Editorial Ciencias Sociales, 2001.

DOSSE, F. La marcha de las ideas: Historia de los intelectuales, historia intelectual. Valencia: Universitàt de Valencia, 2007.

GRAMSCI, A. Los intelectuales y la organización de la cultura. Buenos Aires: Nueva Visión, 1972.

INSTITUTO, d. L. y. L. Historia de la Literatura cubana. La Habana: Editorial Letras Cubanas, 2003. v. 2.

LÓPEZ, O. L. La radio en Cuba (2da Edición ed.). La Habana: Editorial Letras Cubanas, 1998.

MANZONI, C. Un dilema cubano: nacionalismo y vanguardia. La Habana: Fondo Editorial Casa de las Américas, 2001.

MAÑACH ROBATO, J. Historia y estilo. La Habana: Editorial Minerva, 1944.

Terán, O. Amauta: vanguardia y revolución. Historia de los intelectuales en América Latina Argentina: Katz Editores, 2010. v. II.

\section{Dirección}

Yaneidys Arencibia-Coloma

Universidad de Oriente

Via Alterna, Puerto La Cruz 6001

Anzoátegui, Venezuela 